\title{
Retraction Note: Prediction of mountain landslide susceptibility and influencing factors of green landscape design on both sides of roads
}

\author{
Xiaoxiong Wang ${ }^{1} \cdot$ Jinyan Shui ${ }^{1} \cdot$ Zhixian Zhao $^{1}$
}

Published online: 9 December 2021

(c) Saudi Society for Geosciences 2021

Retraction Note: Arabian Journal of Geosciences (2021) 14: 1760

https://doi.org/10.1007/s12517-021-08,186-w

The Editor-in-Chief and the Publisher have retracted this article because the content of this article is nonsensical. The peer review process was not carried out in accordance with the Publisher's peer review policy. Authors Xiaoxiong Wang and Zhixian Zhao have not responded to correspondence regarding this retraction. The Publisher has not been able to obtain a current email address for author Jinyan Shui.

The original article can be found online at https://doi.org/10.1007/ s12517-021-08186-w.

Xiaoxiong Wang

w13609167395@163.com

1 College of Architecture, Chang'An University,

Xi' an 710000, Shanxi, China 